\title{
Visual acuity evaluation in children with hydrocephalus: An electrophysiological study with sweep visual evoked potential
}

\author{
Silvana Alves Pereira ${ }^{1}$, Marcelo Fernandes Costa ${ }^{1,2}$ \\ ${ }^{1}$ Núcleo de Neurociências e Comportamento, Universidade de São Paulo, São Paulo, Brazil \\ ${ }^{2}$ Department Psicologia Experimental, Instituto de Psicologia, Universidade de São Paulo, São Paulo, Brazil \\ Email: costamf@usp.br
}

Received 9 September 2011; revised 2 November 2011; accepted 28 November 2011

\begin{abstract}
The objective was to measure the visual acuity (VA) of children with the diagnosis of hydrocephalus with or without peritoneal-ventricular shunt (PVS). A total of 55 children were included in the study (34 Female), with an age range of 0 to 291 weeks. The VA was measured by the sweep visual evoked potential technique. Of those with a PVS, in 31 the ventricular valve was inserted before 15 days after the diagnosis whereas in 14 the ventricular valve was inserted after 15 days. The sweep VEP was performed in all children, 95 exams (94\%) were abnormal and only 6 were normal. There was a statistical difference in the VA between children with a PVS inserted before 15 days of the diagnosis and children with a PVS after 15 days $(p=0.038)$ or those without a shunt $(p=$ 0.031). Children with no complications of the PVS had a better VA as compared to those with shunt complications $(p<0.001)$. In the group of children with complications, again those who had a shunt inserted before 15 days had better VA results in comparison to those in whom the shunt was inserted after 15 days $(p=0.029)$. No statistical difference in the VA was found between children without the PVS and with those in which the shunt was inserted after 15 days of the diagnosis of hydrocephalus $(p=0.699)$. We conclude that the delayed insertion of the PVS may compromise the visual development of these children.
\end{abstract}

Keywords: Hydrocephalus; Ventricular Shunt; Visual Acuity; Sweep Visual Evoked Potential; Visual Development

\section{INTRODUCTION}

The term hydrocephalus comes from Greek and means "water head". It is a condition in which there is an accumulation of cerebrospinal fluid (CSF). The clinical features of hydrocephalus, especially in the first months of life, is the increase in cranial volume detected by frequent measurements of head circumference, together with the help of appropriate curves and by imaging studies [1].

Children diagnosed with hydrocephalus often present, in addition to visual changes and ocular signs that are very evident from the earliest stages of the disease, failures in the development of cognitive functions. However, the role of the neuropathological abnormalities and complications of hydrocephalus in the genesis of those changes is still poorly understood [2].

Since hydrocephalus is a pathological condition that leads to an ocular and a cognitive impairment, the treatment has been revolutionary since the introduction of surgical implantation of the shunt, with the aim of controlling the mechanisms of CSF drainage of the lateral ventricle of the brain to the peritoneal cavity [3].

The basis of visual health should be structured and strengthened early in life while you can treat and reverse the changes. We face a contradiction: technological breakthrough that benefits the control and diagnosis of hydrocephalus, but little attention to prevention, to ensure the normal visual development in cases of children with large numbers of shunt revisions.

The true incidence of vision loss is not known in this population. There are several studies on the complications of the shunt, but the loss of vision as a complication has not been mentioned in any of these [4-8]. Therefore the aim of our study is to measure visual acuity and verify the effectiveness of the method in children diagnosed with hydrocephalus, with or without shunt and if the time using the derivation presents reflections on visual function, relating possible complications of the shunt and changes in the visual acuity. 


\section{METHODS}

This is a prospective longitudinal study conducted between July 2004 and July 2007 in the Laboratory of Clinical Electrophysiology and Psychophysics of Vision at the Department of Experimental Psychology of the Institute of Psychology at University of São Paulo. We included children age between birth and 6 years diagnosed with hydrocephalus or not, due to intracranial hemorrhage, myelomeningocele or congenital hydrocephalus. They were referred to this study by the University Hospital of the University of São Paulo (HU-USP) and Albert Einstein Hospital (HIAE). Informed consent was obtained from the parents of all infants. The study was approved by the HIAE Ethics Committee (CEP/Einstein $\left.n^{\circ} 04 / 155\right)$.

\subsection{Measurement of Visual Acuity}

The electrophysiological correlates of visual acuity were measured by means of visually evoked potentials, using the NuDiva version of the sweep-VEP system [9-11]. The stimuli were vertical sine wave gratings of 0.2 and $4.0 \mathrm{cpd}$ displayed on a high-resolution video monitor (Dotronix Model EM2400-D788), with a mean luminance of $159.5 \mathrm{~cd} / \mathrm{m}^{2}$, comprising a visual angle of $33.6^{\circ} \times 25^{\circ}$ at the test distance of $50 \mathrm{~cm}$, used for the infants.

The grating acuity was measured by scanning the frequency space in a fixed contrast level $(80 \%)$. Ten linearly spaced spatial frequencies were presented, one per second, starting with the lowest spatial frequency (stripe width). The amplitude of the scan was selected by the experimenter according to the child's age, which could vary their starting and ending value from 0.25 to 25 cycles per degree, as previous normative studies [9]. The reversal rate was $6 \mathrm{~Hz}$ VEP recordings were obtained with EEG electrodes (Grass Gold Disc Electrodes, E6GH, West Warwick, RI, USA) attached to the scalp with electrode cream and cotton pads (Webril II, São Paulo, SP, Brazil). A headband (3M Coban Self-Adherent Wrap 1581, São Paulo, SP, Brazil) was used to keep the electrodes in place. The EEG was recorded from two bipolar placements (O1 and $\mathrm{O} 2), 2-3 \mathrm{~cm}$ to the left and right of a common reference electrode $(\mathrm{Oz})$ placed $1 \mathrm{~cm}$ above the inion on the midline [11]. A ground electrode was placed $2-3 \mathrm{~cm}$ above $\mathrm{Oz}$ according to the ISCEV protocol (André, Norcia). The EEG was amplified with a Neurodata Acquisition System (West Warwick, RI, USA) $(12 \mathrm{C}-4-23$-gain $=10,000 ;-3 \mathrm{~dB}$ cutoff at 1 and $100 \mathrm{~Hz})$.

When the child was alert and looking attentively at the video monitor, the experimenter activated the visual acuity stimulus sequence. The EEG was simultaneously recorded from the two channels and filtered in real time (sampling rate $=397 \mathrm{~Hz}$ ) to isolate the VEP. The recordings were digitized and a discrete Fourier transform
(DFT) was applied to measure amplitude and phase over a $1-\mathrm{Hz}$ band centered on the second harmonic of the visual stimulation frequency. The test was performed binocularly in a darkened room. Throughout each trial small toys hanging in front of the video monitor were moved by the experimenter to attract the child's attention and to maintain its fixation approximately at the center of the screen. A signal-to-noise ratio of 2:1 at peak amplitude for individual trials and 3:1, for the average was required. A threshold was obtained for each channel.

\subsection{Analysis}

The values of visual acuity were expressed in logarithms of base 10, since the development of visual acuity in humans follows a geometric progression [12]. For analysis of the values of Visual Acuity used the difference between the mean logMAR (Table 1-normality limits) and $\log$ MAR found during tests. The children performed up to five exams with an interval of three to four months between each of them. The accuracy of the minimum acuity resolution was obtained by transforming the threshold value, expressed in cycles per degree, to the logarithm of minimum angle of resolution $(\log M A R)$ [9].

The calculation of the difference visual acuity (logMAR found - expected $\log$ MAR) was applied to standardize the ages between patients and facilitate the interpretation of statistical tests. In this case, negative values represent a worse VA than average, and values $\geq$ zero ( 0 ) indicates a normal VA. Statistical analysis was performed in the "Statistica 6.0" software (Tulsa, USA). For the analysis of the values of VA in the different groups (etiology, complications, length of derivation) used the analysis of variance (ANOVA). However for comparison between the values found in the subgroups (with shunt up to 15 days, with shunt $\geq 15$ days and without derivation) we used the comparison test between regressions with sim-

Table 1. Reference values for visual acuity in $\log$ MAR and Snellen equivalent (from Norcia, 1985).

\begin{tabular}{ccccc}
\hline $\begin{array}{c}\text { Gestacional Age } \\
\text { (months) }\end{array}$ & $\begin{array}{c}\text { Minimal } \\
\text { LogMAR }\end{array}$ & $\begin{array}{c}\text { Minimal } \\
\text { Snellen }\end{array}$ & $\begin{array}{c}\text { Mean } \\
\text { LogMAR }\end{array}$ & $\begin{array}{c}\text { Mean } \\
\text { Snellen }\end{array}$ \\
\hline 0 & 1.18 & $20 / 300$ & 0.93 & $20 / 170$ \\
1 & 1.10 & $20 / 250$ & 0.88 & $20 / 150$ \\
2 & 0.93 & $20 / 170$ & 0.7 & $20 / 100$ \\
3 & 0.88 & $20 / 150$ & 0.6 & $20 / 80$ \\
4 & 0.81 & $20 / 130$ & 0.54 & $20 / 70$ \\
5 & 0.78 & $20 / 120$ & 0.48 & $20 / 60$ \\
$6-8$ & 0.65 & $20 / 90$ & 0.3 & $20 / 40$ \\
$9-11$ & 0.60 & $20 / 80$ & 0.3 & $20 / 40$ \\
$12-17$ & 0.48 & $20 / 60$ & 0.18 & $20 / 30$ \\
$18-23$ & 0.35 & $20 / 45$ & 0.1 & $20 / 25$ \\
$24-29$ & 0.24 & $20 / 35$ & 0.1 & $20 / 25$ \\
30 & 0.18 & $20 / 30$ & 0 & $20 / 20$ \\
\hline
\end{tabular}


ple linear regression analysis. The Tukey post-hoc test was applied to identify associations between categorical variables: derivation, complication, etiology, prematurity and gestational age.

\section{RESULTS}

In the period between July 2004 and July 2007, fifty five children with average age of admission to the protocol of 74 weeks $( \pm 78)$, ranging from 2 to 291 weeks met the inclusion criteria and not exclusion. Table 2 shows the demographics of the sample.

Of the 55 children assessed at the 1 st evaluation, 18 performed the 2 nd evaluation, 13 performed the $3 \mathrm{rd}$ evaluation, 10 completed four evaluations and only five completed the five evaluation. The reasons for not achieving the five tests were, in their entirety, did not attend the consultation, without relation to the children health. The average time elapsed between the two tests was 124.7 ( \pm 70.5 days). During the data acquisition time, were performed 101 Visual Evoked Potential tests in all patients studied.

We found 25 patients with hydrocephalus due to intracranial hemorrhage ( $\mathrm{ICH})$ in the neonatal period, 20 patients who had myelomeningocele (Mielo) and ten with hydrocephalus and isolated congenital cause.

The therapeutic approach of hydrocephalus in the sample showed some variation in the type of intervention and the time of the intervention. In this sense, of the 55 babies studied, forty-five (81.8\%) underwent ventriculoperitoneal shunt (VPS), whereas $10(18.2 \%)$ had an exclusively clinical management. Those submitted to the VPS, the median time to intervention after the diagnosis of hydrocephalus was 16 days ( \pm 21.79 days), ranging from 1 day to 121 days. Stratifying the time for the installation of VPS and calculating the cutoff time to bypass, as proposed by Fobe [8] and Heinsenbergen [13],

Table 2. Demographic data for patients.

\begin{tabular}{ll}
\multicolumn{1}{c}{ Variable } & \multicolumn{1}{c}{ Value } \\
\hline Age (weeks): 1st test (mean \pm SD) & $74 \pm 78$ \\
Females: $n(\%)$ & $34(61.8 \%)$ \\
Birth Weight (mean \pm SD in grams) & $2289.5 \pm 1144.7$ \\
Low birth weight: $\mathrm{n}(\%)$ & $30(54.5 \%)$ \\
Very Low birth Weight: $\mathrm{n}(\%)$ & $19(34.5 \%)$ \\
Gestational Age (mean \pm SD) & $34 \pm 5$ \\
Premature: $\mathrm{n}(\%)$ & $32(58.2 \%)$ \\
Term: $\mathrm{n}(\%)$ & $23(41.8 \%)$ \\
Corrected Age at the 1 st test: $\mathrm{n}(\mathrm{mean} \pm \mathrm{SD})$ & $68 \pm 78$ \\
\hline
\end{tabular}

$\mathrm{SD}=$ standard deviation; $\mathrm{n}$ : total cases; Corrected Age $=(40$ weeks of gestational age). we found that thirty-one children $(56.3 \%)$ had the procedure performed less than 15 days of diagnosis of hydrocephalus while in $14(25.4 \%)$ the shunt was installed after 15 days of diagnosis and $10(18.1 \%)$ children were not derived.

All children had a first measurement performed successfully. Nine five tests $(94 \%)$ were reduced and six $(6 \%)$ had a normal result. When comparing the number of normal exams in the five intermittent ratings only $1^{\circ}$ and $2^{\circ}$ evaluation had normal values. The implant of the shunt was not homogeneous considering the time between dignosis and surgery we design the cutoff to 15 days. The Figure 1 presents the results of the initial VA evaluation obtained from 10 children diagnosed with hydrocephalus without shunt (labeled 0) 31 children who were deriving less than 15 days (labeled 1) and 14 children who were deriving more than 15 days (labeled 2). There is no statistical difference between the VA shunt without children compared with children with bypass time greater than 15 days $(F=0.98 ; p=0.699)$. Differences in VA, however, were found comparing children whose shunts were performed within 15 days of diagnosis of hydrocephalus, with those whose shunt was performed after 15 days $(F=8.52 ; p=0.038)$ or those that were not derived $(\mathrm{F}=13.07 ; \mathrm{p}=0.031)$ (Figure 1).

It was verified that 37 children no surgical complications and/or medication to control the DVP system, 45 underwent a shunt implant had some type of complication. Among the complications between the 1st and 2nd examinations, we found that the obstruction and infectionas the cause, all of which occurred in different ways during the study period.

Comparing the results of the VA of 18 children without complications with the 37 children with complications,

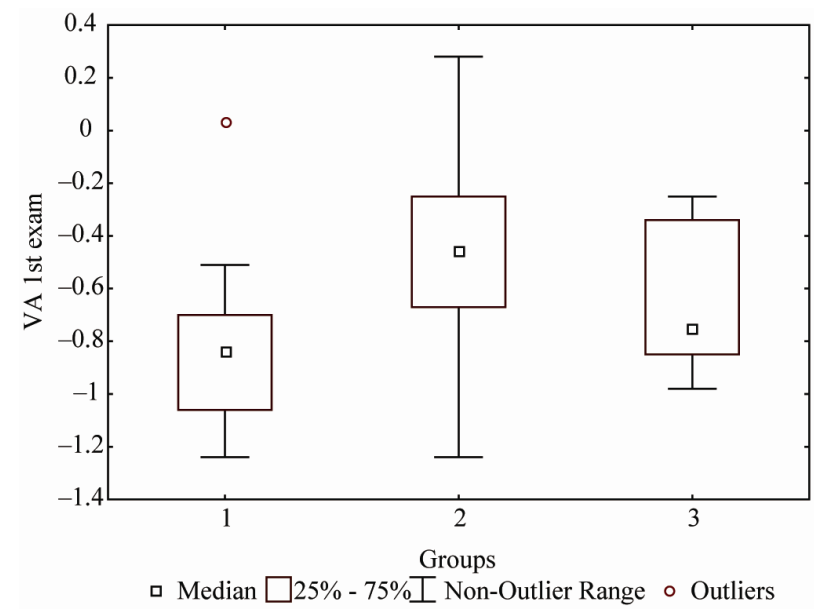

Figure 1. Comparison between groups with different types of intervention, where: " 0 " (10 children without derivation), "1" (31 crianças derivation with time $\leq 15)$ and " 2 " (14 children who were shunt $\geq 15)$. Group 1 showed statistical difference when compared with group $0(\mathrm{p}=0.038)$ and $1(\mathrm{p}=0.031)$. 
we observed that the VA of the group without complications was statistically the better than the group with complications $(p<0.001)$. With the evolution of the study realize that the 37 children who had some type of complication such as obstruction or infection during the 1 st evaluation, only seven children $(13.5 \%)$ had positive results regarding their medical treatment after the $1 \mathrm{st}$ evaluation and did not returned for the 2 nd examination.

In the analysis of the VA evolution, we considered as an important variable the time between the shunt installation and the diagnosis of any neurologic complication, if had happened. Our results shows that the earlier the complication was installed the worse the results of VA were measured. So, those children in which there was some complication on the first or second visual measurement, there was a greater impairment of visual function than those children, in which the shunt complication was defined only in the third evaluation and so on, comparing subsequent evaluations.

Among the 13 children who underwent the 3rd examination, seven children had any complications since the second evaluation, two children the complication was installed only in that evaluation and four had no complications in the two periods. The Figure 2 shows the evolution of VA of the children between 2 nd and $3 \mathrm{dr}$ visual assessment and represents the data described above. It is important to address here that we were unable to perform comparisons including older evaluations due to the low number of subjects who return to those examinations.

Once we detected that the presence of complications and the time for completion of ventriculoperitoneal shunt as clear determinants a more committed visual acuity, we included a correlation analysis considering these two factors aiming to determine which of these factors imposes the greatest impact in reducing of visual function.

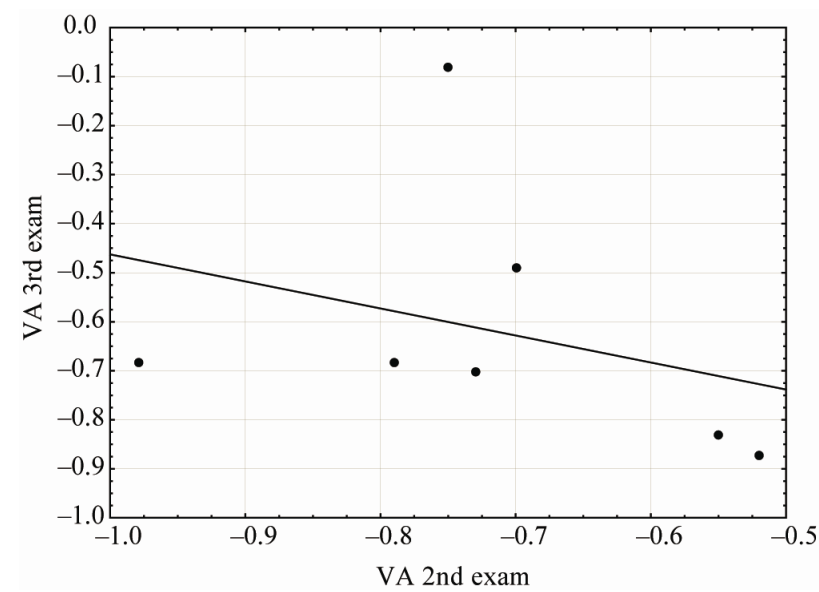

Figure 2. VA average of seven children who presented complications in 2nd and 3rd tests. Each dot shows the VA for a child and the black continuous line, the regression.
We compared the group of children with complications considering how many derivations they were underwent. The group of children in which the shunt was implanted with a shorter time than 15 days from the hydrocephalus diagnosis, they presented a statistically better results of VA compared to the children whose the shunt implantation was performed with more than 15 days of diagnosis $(\mathrm{F}=5.38 ; \mathrm{p}=0.029)$ (Figure 3).

We also compared the VA of 10 children who have not been derived. We observed in the VA scores of those children a negative trend over time. The data relating to analysis of etiology and gestational age variables on the outcome of VA were not statistically different $(\mathrm{p}=0.875$ and $\mathrm{p}=0.865$, respectively).

\section{DISCUSSION}

The normal visual acuity depends on the integrity of the central nervous system Increased cranial pressure due to hydrocephalus is one of the factors that most often negatively affects the visual function. One of the first studies to describe the visual impairment as a result of hydrocephalus was published in 1768 by Robert Whytt. In that work, the authors found an incidence of strabismus between $60 \%$ - $75 \%$ of children with hydrocephalus studied [5] that is higher than in normal population (around 3\% - 4\%).

The assessment of visual acuity in children with hydrocephalus has not been frequently studied and, as a logical consequence, there are few studied regarding to the visual functions and even fewer that follow those children as we did. The studies involving children with a diagnosis of hydrocephalus are mostly series of retrospective case and they consider different etiologies as a unique group [13-15].

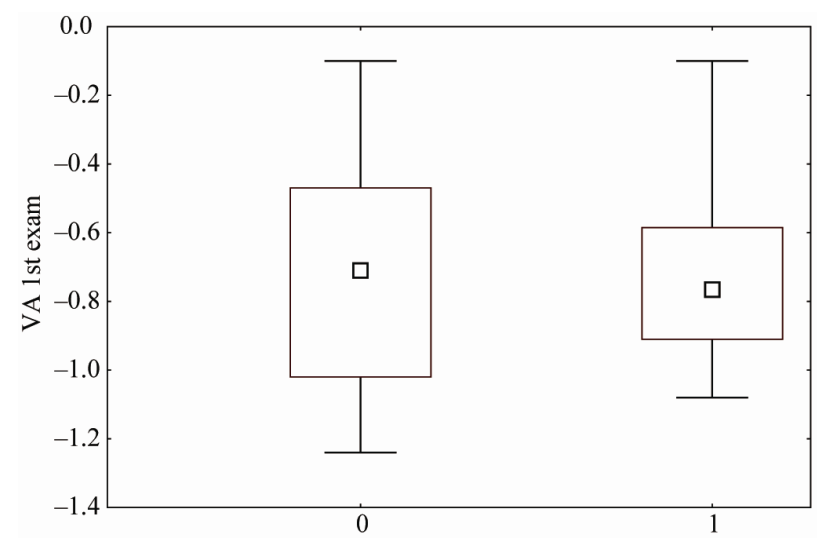

Figure 3. VA comparison for the 37 children who's had derivation after the 1st exam. The Box-Plot labeled 0 shows the VA of the 25 children who drifted time was $\leq 15$ days and the BoxPlot labeled 1 show the 12 children who drifted time was $>15$ days. The outcomed VA was statistically better for group $0(\mathrm{p}=$ $0.030)$. 
Among the fifty-five children studied forty-five were derived. Considering the complications arising from the presence of PVD, we noticed that a large proportion of children in this group (a total of thirty-seven) suffered some complication. Considering the complications presented in our sample, we found that thirty-six were due to obstruction and infection that occurred between the VA measurements.

Kliemann and Rosemberg [16] claim in their study that the infection and mechanical malfunction of the shunt system are the main complications of PVD. Mechanical complications such as obstruction of the drainage catheter, have been reported with a frequency between $30 \%$ and $60 \%$, occurring most frequently in the first two years after bypass.

The infection rate of the drainage system varies between $2 \%$ and $15 \%$, with a major influence on morbidity and quality of life of patients and in mortality risk that could be as higher as $30 \%-40 \%$. An interesting finding in our study was the fact that the group with no shunt complications presented better values of visual acuity compared to those group in which the complications had occurred.

Another important factor related to complications and their impact on the visual system is the fact that the more complications in the shunt system the greater the reduction in the development of visual acuity with the passing of time, since the values of visual acuity values remained similar against the expectation of an evolution of this function, normally observed in normal children with those ages.

Children who experienced complications in the period comprising two consecutive tests of visual acuity, the values measured were lower than those children who had complications in only one examination. Again, we found in the literature which correlates the number of complications of PVD with visual function over time.

We obtained results showing that the time between diagnosis and surgery to perform the bypass impairs the visual function. We are lead to conclude it since children who had a latency greater than 15 days between diagnosis and the need to the bypass procedure, had the worst values of visual acuity. This finding is of great impact and gives more information to consider one that can help medical staffs when deciding on the procedures to be performed in those children, mainly surgeries.

Several retrospective studies follow the progress of children diagnosed with hydrocephalus treated surgically versus the time of installation of the valve, but in these, neurological and cognitive development are the only focus of the investigations [8,13,17-19].

Many risk factors have been reported as an etiology of hydrocephalus associated with pathology, complications such as shunt infection and number of cirurgical revisions and to our knowledge, no study has prospectively measured the visual acuity in this population. In our study, the procedures for derivation and complications occurred during the achievements of visual acuity, which allowed us to study their evolution and impact of these factors in this visual function.

The time of derivation as a complicating factor for children diagnosed with hydrocephalus treated surgically was described in the work of Heinsenbergen [13]. The authors aimed to find the main risk factors for children with hydrocephalus and correlate the shunt time with the results of a questionnaire used by the World Health Organization (WHO) to the international classification and evaluation of injuries and disabilities: injuries from hearing, vision, musculoskeletal, speech and language disorders and epilepsy. This study retrospectively evaluated 137 children and the authors concluded that the time of implantation of the bypass valve is what defines the prognosis of children with hydrocephalus treated surgically. Children who were derived in longer than 30 days had poor response in all items of the WHO questionnaire, except hearing. As the focus of her work was not to evaluate visual acuity and the data were collected retrospectively, the authors do not make clear what the changes were found in each of the items evaluated by questionnaire.

The impact of shunt time on cognitive functions has already been studied by Fobe [8], showing that there are cognitive impairments in children with shunt after seven days of diagnosis of the need for bypass.

Our results agree with these studies, since it shows a reduction in visual acuity of children who were derived more than 15 days compared with the group of children drifted up to 15 days. Our data related to the findings of Fobe et al., [8] and Heinsenbergen et al. [13] suggest that the time between diagnosis and the derivation need to be as short as possible to reduce losses of cortical functions, since our results suggest that the shorter this period, the better the visual acuity measured. The visual acuity of children who were not derived showed values that were below expectations, suggesting an subclinical impairment possibly due to the increased pressure.

A total of 10 children in our study did not undergo surgical treatment for control of hydrocephalus, since in those situations there were the compensation of hydrocephalus. The bony structures of the babies are malleable and can be expanded and therefore control the increased intracranial pressure and compensate for hydrocephalus, but this flexibility is limited in time and what was offset becomes harmful, compressing visual pathways and causes damage to the development of visual function. Indeed, this compensatory mechanism was not efficient in our sample. When comparing the values of visual acuity in this group with the group derived with time less 
than 15 days, we observed worse results in the group without derivation. This may be due to several factors, but we believe that the compensation made by the expansion of the cranial bones was not enough to reduce the total pressure. Thus, the damage caused by the pressure slightly increased and persisting for many years, continuously affect the structures of the visual system and lead to poor visual acuity that we found in our children.

Moreover, Caines [5] followed by three years, 20 children diagnosed with Myelomeningocele associated with hydrocephalus. The purpose was to describe the findings of neurological spectrum in the first four years in the group with and without shunts. The results revealed few abnormalities between the two groups and none of the children without derivation presented defective oculo-motor function. Data analysis is hampered by this author since the author does not describe the number of revisions made in each child who required shunt and also does not describe the time between diagnosis and first shunt insertion. Another important consideration to make is that this study does not contradict our results showing differences between the groups derived and not derived.

The ocular changes observed in the clinical neurological or neurophthalmological exam are unclear. Several studies in our laboratory show changes in visual functions in many neurological patients with normal ophthalmologic diagnosis [20-22].

Since the presence of complications and time insert of the DVP are determinants for a visual acuity more impaired, we studied the correlation of these two factors together in an attempt to determine which of these factors imposes the greatest impact in reducing the visual function. Our data show that the group of children was derived with a time less than 15 days of diagnosis of hydrocephalus presented results of visual acuity was statistically superior to children whose derivation was performed after of the 15 days. We did not found in the literature similar results or even data that confront our results.

The comparative analysis considering the factors such as etiology, birth weight and gestational age showed no correlation with the value of visual acuity. Differently from the data described in the literature [23-25] our results show that the value of visual acuity was not different among the groups studied, myelomeningocele, hydrocephalus and intraventricular hemorrhage alone. The three groups showed values lower than normal visual acuity, but no statistical difference between them. Considering the data of our sample, the congenital and acquired etiologies had the same negative impact in the visual function.

Shokunbi [26] evaluated the visual function of children diagnosed with hydrocephalus of different etiologies and found similar impairment in visual acuity compared to our results. The authors evaluated 20 children diagnosed with hydrocephalus and different etiologies and an average age below 18 months. Those authors concluded that the ventricular dilation factor is independent of visual damage to the diagnosis of origin of hydrocephalus. However, they found the greater the ventricular dilation, increased the risk of impaired visual function.

In short, existing studies regarding the long-term monitoring of patients with hydrocephalus are exclusively retrospective, making it difficult to compare them both because of different methodologies for data collection and evaluation of visual function, as the analysis of longterm impact treatment of hydrocephalus in the prognosis of patients.

The inclusion of many etiologies for hydrocephalus in different studies without their express analysis as an important factor for understanding the functional visual picture of the disease and the multiple influences on the sample also represent an obstacle to comparative studies. Our work was the first to prospectively evaluate the visual acuity of children diagnosed with hydrocephalus treated surgically during the first years of life, and to correlate the result with the time and number of shunt complications.

Despite the great technological progress achieved by the ophthalmology, we are still unable to prevent changes detectable by simple visual examination of visual acuity in children with hydrocephalus. The indication of the bypass valve and treatment for the complications are still delayed measures due to prematurity, hemodynamic instability and no authorization by the family. These reasons may compromise the visual development of these children and consequently alter their motor development and their ability to social interactions, comunications and language since gestures and social behaviors are perceived by the visual response.

Vision is one of the most important senses in normal physical and cognitive development of children. The child needs to develop your vision, and until VA is fully established, around the end of the first decade of life, any obstacle to the formation of image or an eye misalignment, can lead to poor visual development, which will become irreversible if not treated on time. The early onset of bypass valve, effective treatment to minimize the number of complications and a program of early visual stimulation, allows the child to have greater interaction with their environment.

In summary, visual acuity was measured successfully in children with hydrocephalus by the method of sweep VEP. The time between diagnosis and need for bypass surgery and the complications after bypass are critical factors to be considered for a visual prognosis and must be in mind during the surgery planning. 


\section{ACKNOWLEDGEMENTS}

We would like to thank Prof. Russell David Hamer for his invaluable discussions and suggestions in the whole paper. This research was supported by grants to MFC from CNPq 401153/2009-6 Ciências Humanas. MFC is CNPq research fellow.

\section{REFERENCES}

[1] Tzekov, S. and Cherninkova, T.G. (1991) Neuroophthalmological symtoms in children treated for internal hydrocephalus. Pediatric Neurosurgery, 17, 317-320. doi:10.1159/000120617

[2] Cedzich, C., Schramm, J. and Wenzel, D. (1990) Reversible visual loss after shunt malfunction. Acta Neurochirurgica, 105, 121-123. doi:10.1007/BF01669994

[3] Sutton, L.N., Sun, P. and Adzick, N.S. (2001) Fetal neurosurgery. Neurosurgery, 48, 124-142. doi:10.1097/00006123-200101000-00023

[4] Biglan, A.W. (1995) Strabismus associated with meningomyelocele. Journal of Pediatric Ophthalmology and Strabismus, 32, 309-314.

[5] Caines, E., Dahl, M. and Holmstro, G. (2007) Longterm oculomotor and visual function in spina bifida cystica: A population-based study. Acta Ophthalmologica Scanddinavica, 85, 662-666. doi:10.1111/j.1600-0420.2007.00905.x

[6] Cedzich, C., Schramm, J. and Wenzel, D. (1992) Reversible visual loss after shunt malfunction. Acta Neurochirurgica, 105, 121-123. doi:10.1007/BF01669994

[7] Cronemberger, M.F., Tabuse, M.K.U., Aguilar, L.T., Costa, M.F. and Ferraretto, I. (1999) Achados oculares em pacientes com mielomeningocele: 72 casos. Arquivos Brasileiros, Oftalmologia, 63, 379-382. doi:10.1590/S0004-27492000000500010

[8] Fobe, J.L., Rizzo, A.M.P.P., Silva, I.M., Silva, S.P.M., Teixeira, C.E., Souza, A.M.C. and Fernandes, A. (1999) QI em pacientes com hidrocefalia e mielomeningocele: Implicações do tratamento cirúrgico. Arquivos de NeuroPsiquiatria, 57, 44-50.

doi:10.1590/S0004-282X1999000100009

[9] Norcia, A.M. and Tyler, C. (1985) Spatial frequency sweep VEP: Visual acuity during the first year of life. Vision Research, 25, 1399-1408. doi:10.1016/0042-6989(85)90217-2

[10] Costa, M.F., Ventura, D.F., Salomão, S.R., Berezovsky, A., De Haro, F.M. and Tabuse, M.K.U. (2001) Grating acuity measured by sweep VEP in children with spastic cerebral palsy. Investigative Ophthalmology \& Visual Science, 42, 4536.

[11] Costa, M.F., Salomao, S.R., Berezovsky, A., De Haro, F.M. and Ventura, D.F. (2004) Relationship between vision and motor impairment in children with spastic cerebral palsy: New evidence from electrophysiology. Behavioral Brain Research, 149, 145-150. doi:10.1016/S0166-4328(03)00223-7

[12] Holladay, J.T. (1997) Proper method for calculating average visual acuity. Journal of Refractive, Surgery, 13,
388-390.

[13] Heisensbergen, I., Rottevell, J., Roeleveld, N. and Grottenhuis, A. (2002) Outcome in shunted hydrocephalic children. European Journal of Paediatric Neurology, 6, 99-107. doi:10.1053/ejpn.2001.0555

[14] Paysse, E.A., Khokhar, A., McCreery, K.M.B., Morris, M.C. and Coats, D.K. (2002) Up-slating palpebral fissures and oblique astigmatism associated with a-pattern strabismus and overdepression in adduction in spina bifida. Journal of AAPOS, 12, 354-359.

doi:10.1067/mpa.2002.129042

[15] Reinprecht, A., Dietrich, W., Berger, A., Bavinzski, G., Weninger, M. and Czech, T. (2001) Posthemorrhagic hydrocephalus in preterm infants: Long-term follow-up and shunt-related complications. Child's Nervous System, 13, 663-669. doi:10.1007/s00381-001-0519-2

[16] Kliemann, S.E. and Rosemberg, S. (2005) Hidrocefalia derivada na infância: Um estudo clínico-epidemiológico de 243 observações consecutivas. Arquivos de Neuro-Psiquiatria, 63, 494-501. doi:10.1590/S0004-282X2005000300024

[17] Vinck, A., Maassen, B., Mullaart, R. and Rotteveel, J. (2006) Arnold-Chiari-II malformation and cognitive functioning in spina bifida. Journal of Neurology, Neurosurgery, and Psychiatry, 77, 1083-1086. doi:10.1136/jnnp.2005.075887

[18] Gabrieli, A.P.T., Vankoski, S., Dias, L.C., Milani, C. and Lourenço A. (2004) Análise laboratorial de marcha na mielomeningocele de nível lombar baixo e instabilidade unilateral de quadril. Acta Ortopédica Brasileira, 12, 91-99.

[19] Ladewig, I. (2000) A importância da atenção na aprendizagem de habilidades motoras. Revista Brasileira de Educação Física e Esporte, 3, 62-71.

[20] Ventura, D.F., Gualtieri, M., Oliveira, A.G.F., Costa, M.F., Quiros, P., Salomão, S.R., Berezovsky, A., Sadun, F., Sadun, A.A. and Carelli, V. (2007) Male prevalence for color vision defects in leber's hereditary optic neuropathy. Investigative Ophthalmology \& Visual Science, 48, 2362-2370. doi:10.1167/iovs.06-0331

[21] Costa, M.F., Oliveira, A.G.F., Feitosa-Santana, C., Zatz, M. and Ventura, D.F. (2007) Red-green color vision impairment in duchenne muscular dystrophy. American Journal of Human Genetics, 80, 1064-1075. doi:10.1086/518127

[22] Moura, A.L.A., Teixeira, R.A.A., Oiwa, N.N., Costa, M.F., Callegaro, D., Hamer, R.D. and Ventura, D.F. (2008) Chromatic discrimination losses in multiple sclerosis patients with and without optic neuritis using the cambrigde color test. Visual Neuroscience, 25, 463-468. doi:10.1017/S0952523808080437

[23] Spencer, R.M.D. (2006) Long-term visual outcomes in extremely low-birth-weight children. Transactions of the American Ophthalmological Society, 104, 493-516.

[24] Graziano, R.M. and Leone, C.R. (2002) Problemas oftalmológicos mais freqüentes e desenvolvimento visual do pré-termo extremo. Jornal de Pediatria, 81, 95-100.

[25] Guerra, A.B., Diniz E.M.A., Krebs, V.L.J., Ceccom, M.E.J., Ferbaum, R., Vaz, F.A.C. and Ramos, J.L.A. (1995) Estudo clínico-evolutivo de 63 recém-nascidos 
portadores de hemorragia intracraniana. Pediatria, 17, 117-122.

[26] Shokumbi, M.T., Odebode, T.O., Agbeja-Baiyeroju, A.M., Malomo, A.O., Ogunseyinde, A.O. and Familusi, J.B.
(2002) A comparison of visual function scores in hydrocephalic infants with and without lumbosacral myelomeningocoele. Eye, 16, 739-743. doi: $10.1038 /$ si.eye. 6700085 